\title{
Morphology and Morphometry of the Hyoid Bone in a Black South African Population
}

\author{
Morfología y Morfometría del Hueso Hioides en una Población Sudafricana Negra
}

\author{
M. O. Shangase ${ }^{1}$; S. Ishwarkumar ${ }^{2} \&$ P. Pillay ${ }^{1}$
}

SHANGASE, M. O.; ISHWARKUMAR, S. \& PILLAY, P. Morphology and morphometry of the hyoid bone in a black South African population. Int. J. Morphol., 39(1):134-137, 2020.

SUMMARY: The hyoid is a unique, ' $U$ ' shaped bone, located on the anterior aspect of the neck, between the mandible and thyroid cartilage. This bone displays morphological and morphometric characteristics that can assist in determination of age, sex and race of an individual.Therefore, the present study aimed to investigate the morphology and morphometric parameters of the hyoid bone in a Black South African population of KwaZulu-Natal. The morphological and morphometric parameters of the 40 hyoid bones obtained from the Department of Clinical Anatomy, University of KwaZulu-Natal were classified in accordance with Deepak et al. (2013). In this study, $35 \%$ of hyoid bones were ' $U$ '- shaped and $65 \%$ were ' $V$ '- shaped in males, whereas in the female specimens, $70 \%$ of hyoid bones were ' $U$ '- shaped and $30 \%$ 'V'- shaped. Furthermore, this study recorded a statistically significant relationship between the shape of the hyoid bone and sex. With regard to the morphometry, the width of the hyoid bone was greater in males than females however; the length of the hyoid bone was greater in females than males. In addition, this study concludes that these results may contribute to the existing knowledge on the morphology and morphometry of the hyoid bone and may assist forensic procedures.

KEY WORDS: Hyoid bone; South African Black population; Morphology and morphometry.

\section{INTRODUCTION}

The hyoid bone is typically a ' $U$ '-shaped bone present in the anterior aspect of neck at the level of the fourth cervical vertebra, located between the mandible and thyroid cartilage (Moore et al., 2014). Anatomically, it can be divided into 3 parts, viz. two greater cornu, a body and two lesser cornu (Leksan et al., 2005). Literary reports states that the hyoid bone is a unique bone in the human skeleton, as it does not articulate directly with any other bone (Leksan et $a l$.). It is attaches and supported by muscles and ligaments within the neck region (Leksan et al.).

Literature has documented variations that are present in the human skeletal system amongst different population groups around the world (Ubelaker \& DeGaglia, 2017). The hyoid bone is one of the bones that has been classified to display sexually dimorphic features (Reesink et al., 1999; Mukhopadhyay, 2010). Leksan et al. classified the morphology of the hyoid bone as being more asymmetrical in females as compared to males however; Deepak et al. reported that the hyoid bones of males displayed asymmetrical shapes as compared to the females. Balseven-
Odabasi et al. (2013) and Logar et al. (2016) concluded that the hyoid bone can be utilized to determine the sex of an individual in a Turkish and contemporary White population. Kindschuh et al. (2012) recorded ancestral differences in skeletal material of the African and the European population, whereby the hyoid bone of African descent was more elongated as compared to those of the European population, with the latter generally having larger hyoid bones.

Soltani et al. (2017) documented that the morphometry of the hyoid bone may be utilized to determine the sex of an individual. Furthermore, Okasi et al. (2018) stated that due to the sexual dimorphic features of the hyoid bone, it is viable option for sex determination, as this study further documented that the hyoid bones of males have a greater width, antero-posterior length and slope of cornua, as compared to the females.

Torimitsu et al. (2018) further encourages researchers to conduct more studies on the hyoid bone and its potential in determining age, sex, race and cause of death, within

\footnotetext{
${ }^{1}$ Department of Clinical Anatomy, School of Laboratory Medicine and Medical Sciences, College of Health Sciences, University of KwaZulu-Natal, Westville Campus, South Africa.

${ }^{2}$ Department of Human Anatomy and Physiology, Faculty of Health Sciences, University of Johannesburg, Doornfontein Campus, South Africa.
} 
different population groups. Therefore, this study aimed to document the morphological and morphometric parameters of the hyoid bone within the Black South African.

\section{MATERIAL AND METHOD}

This study examined 40 hyoid bones (Male=20, Female $=20$ ) obtained from the Department of Clinical Anatomy, University of KwaZulu-Natal (Westville \& Nelson $\mathrm{R}$ Mandela School of Medicine campuses). Ethical clearance was obtained (BE366/19). This study excluded any fragmented or damaged hyoid bones.

The morphological and morphometric methodology employed in this study was adapted from Deepak et al. The data was analysed using SPSS (Version: 15). The chi-square test and the T-test were utilized to determine if there were any statistical significance differences. A p-value $<0.05$ was deemed statistically significant.

Morphology of the hyoid bone methodology: The hyoid bone was classified in accordance with Deepak et al. as either ' $U$ '-shaped (if the width is equal to or less than the length) or ' $\mathrm{V}$ '-shaped (if the width of the hyoid bone is greater than the length) (Fig. 1).

Morphometry of the hyoid bone methodology: The following morphometric parameters were measured using a digital calliper in accordance with Deepak et al.:
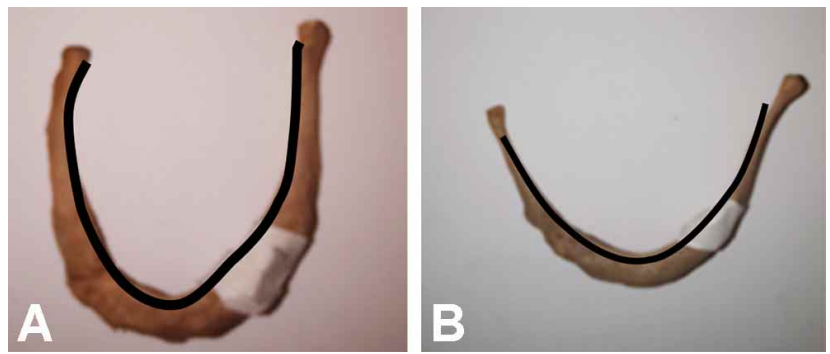

Fig. 1. (1) 'U'- shaped hyoid bone and (2) 'V'-shaped hyoid bone.
- Width of the hyoid bone (WD): Lateralmost distance between the greater cornua (a - b) (Fig. 2).

- Length of the hyoid bone (L): Middle distance from the anterior aspect of the body of the hyoid bone (c), to the point lying mid-way between the distances of the greater cornua (a - b) (Fig. 2).

Reliability and validity: Each morphometric parameter was measured three times by the first author and the mean value was calculated to ensure validity and reliability of this study.

\section{RESULTS}

Morphology of the hyoid bone: This study examined 40 hyoid bones, the ' $U$ '-shaped hyoid bone more prevalent than the ' $\mathrm{V}$ '-shaped hyoid bone, with an incidences of $52.5 \%$ and $47.5 \%$, respectively (Table I). The present study documented that $35 \%$ and $65 \%$ of the males had a ' $U$ 'shaped and ' $V$ '-shaped hyoid bones, respectively (Table I). However, 'U'-shaped hyoid bone was most prevalent among the females in this study, with an incidence of $70 \%$, while the remaining $30 \%$ of female hyoid bones was ' $\mathrm{V}$ '-shaped (Table I). This study found a statistically significant relationship between the shape of the hyoid bone and sex, with a p-value of 0.027 .

Morphometry of the hyoid bone: The mean width of the hyoid bone ranged between $29.56 \mathrm{~mm}-52.84 \mathrm{~mm}$ in males and $29.83 \mathrm{~mm}-44.88 \mathrm{~mm}$ in the female. The width of the hyoid bone was greater in males than females with a mean value of $37.07 \mathrm{~mm}$ and $36.75 \mathrm{~mm}$, respectively (Table II).

However, the mean length of the hyoid bone was greater in females $(37.45 \mathrm{~mm})$ than males $(35.70 \mathrm{~mm})$ (Table II). This study found no statistical significant difference between the width and length of the hyoid bone and sex, with p-values of 0.826 and 0.932 , respectively.
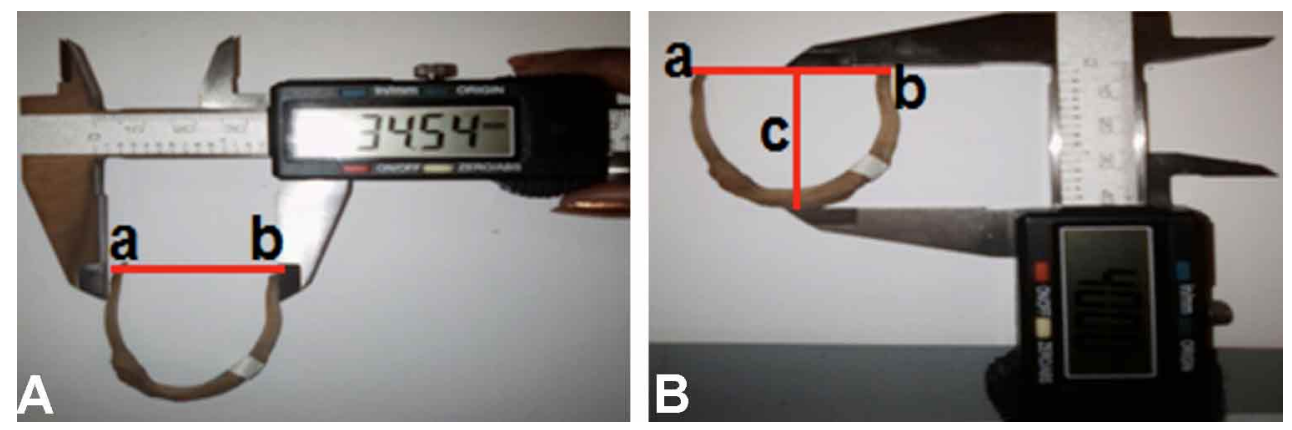

Fig. 2. (1) Width of the hyoid bone and (2) the Length of the hyoid bone. 
Table I. Shape of the hyoid vs sex.

\begin{tabular}{ccccc}
\hline Shape & Male $(\mathrm{n}=20)$ & Female $(\mathrm{n}=20)$ & Total $(\mathrm{n}=40)$ & $\mathrm{p}$-value \\
\hline 'U'-shaped & $7(35 \%)$ & $14(70 \%)$ & $21(52.5 \%)$ & 0.027 \\
'V'-shaped & $13(65 \%)$ & $6(30 \%)$ & $19(47.5 \%)$ & \\
\hline
\end{tabular}

Table II. Morphometric parameters of the hyoid vs sex.

\begin{tabular}{ccccc}
\hline $\begin{array}{c}\text { Morphometric } \\
\text { parameter }\end{array}$ & Male & $\begin{array}{c}\text { Standard } \\
\text { deviation }\end{array}$ & Female & $\begin{array}{c}\text { Standard } \\
\text { deviation }\end{array}$ \\
\hline Mean width & 37.07 & 4.7832 & 36.75 & 3.8864 \\
Mean length & 35.70 & 3.3170 & 37.45 & 3.0549 \\
\hline
\end{tabular}

Table III. Literature comparison between the shape of the hyoid bones and sex.

\begin{tabular}{crrrrr}
\hline \multicolumn{1}{c}{ Study } & Year & \multicolumn{2}{c}{ Male } & \multicolumn{2}{c}{ Female } \\
& & 'U'- shape & 'V'- shape & 'U' - shape & 'V'- shape \\
\hline Leksan et al. & 2005 & $45.7 \%$ & $48.6 \%$ & $42.8 \%$ & $34.3 \%$ \\
Deepak et al. & 2013 & $44.0 \%$ & $56.0 \%$ & $55.0 \%$ & $45.0 \%$ \\
Present study & 2019 & $35.0 \%$ & $65.0 \%$ & $70.0 \%$ & $30.0 \%$ \\
\hline
\end{tabular}

\section{DISCUSSION}

In the identification process of a deceased person determining the sex, age and race of the deceased is of vital importance (Okasi et al.). Okasi et al. further stated that due to the sexual dimorphic features of the hyoid bone, it is a feasible choice for sex determination of an individual.

Morphology of the hyoid bone: This study reported that the ' $\mathrm{V}$ '-shape hyoid bone was most prevalent in males $(65 \%)$, while the ' $U$ '-shape is most prevalent in females (70 \%) (Table III). These findings correlate with previous studies by Leksan et al. and Deepak et al. (Table III).The present study also recorded a statistically significant relationship between the shape of the hyoid bone and sex $(\mathrm{p}$-value $=0.027)$.
Morphometry of the hyoid bone: In this study, the mean width of the hyoid bone in males were greater than female, which correlated with previous literature (Leksan et al.; Mukhopadhyay; Soltani et al.) (Table IV). In the present study, the mean length of the hyoid bone was great in females than males with a mean value of $37.46 \mathrm{~mm}$ and $35.70 \mathrm{~mm}$, respectively (Table IV).This finding correlated with the study conducted by Kopuz \& Ortug (Table IV).However, Leksan et al., Kim et al. (2006), Mukhopadhyay, Balseven-Odabasi et al. and Soltani et al. reported that the length of hyoid bones in males was greater than their female counterparts (Table IV). Despite differences in the width and length of the hyoid bone between males and females, this study recorded no statistically significant relationship between these two parameters, with p-values of 0.826 and 0.932 , respectively.

Table IV. Literature comparison of morphometric parameters of the hyoid bone.

\begin{tabular}{lccccccc}
\hline \multicolumn{1}{c}{ Study } & Year & \multicolumn{2}{c}{ Samplesize } & \multicolumn{2}{c}{ Mean width $=$ STD Dev } & \multicolumn{2}{c}{ Mean length \pm S TD Dev } \\
& & Male & Female & Male & Female & Male & Female \\
\hline Leksan et al. & 2005 & 35 & 35 & $45.80 \pm 6.7$ & $40.50 \pm 6.4$ & $41.40 \pm 4.1$ & $35.8 \pm 3.9$ \\
Kim et al. & 2006 & 52 & 35 & $45.8 \pm 12.8$ & $35.4 \pm 16.1$ & $39.7 \pm 3.2$ & $33.9 \pm 6.6$ \\
Mukhopadhyay & 2010 & 73 & 71 & $40.66 \pm 3.42$ & $37.15 \pm 3.92$ & $29.63 \pm 3.9$ & $22.32 \pm 2.1$ \\
Balseven-Odabasi et al. & 2013 & 53 & 32 & $49.16 \pm 6.79$ & $42.44 \pm 9.12$ & $44.56 \pm 5.03$ & $38.66 \pm 5.07$ \\
Kopuz \& Ortug & 2016 & 46 & 14 & $41.31 \pm 6.03$ & $37.56 \pm 4.36$ & $28.30 \pm 4.34$ & $28.76 \pm 4.73$ \\
Soltani et al. & 2017 & 173 & 176 & $38.71 \pm 1.92$ & $30.26 \pm 2.18$ & $38.97 \pm 1.43$ & $30.33 \pm 2.01$ \\
Present study & 2019 & 20 & 20 & $37.07 \pm 4.8$ & $36.7 \pm 3.9$ & $35.70 \pm 3.3$ & $37.46 \pm 3.05$ \\
\hline
\end{tabular}

\section{CONCLUSION}

Although the hyoid bone is small and fragile, when used in conjunction with other bones of the body, this bone may be utilized to assign age, sex and race (Kindschuh et $a l$. .).This study recorded that the hyoid bone may be utilized to determine the sex of an individual, as a statistically significant relationship was documented between the 
morphology of the hyoid bone and sex. Furthermore, the results of this study may contribute to the existing knowledge available on the morphology and morphometry of the hyoid bone and may assist forensic medicine.

\section{Fuuture Recommendation}

The inclusion of age as a parameter is recommended for future studies, as this may add to the reliability of the study. Since, South Africa is a multiracial country, the documentation of the other ethnic groups is also warranted to ensure that population-specific data is available.

\section{ACKNOWLEDGEMENTS}

"Dr P Pillay is a University of KwaZulu-Natal (UKZN) Developing Research Innovation, Localisation and Leadership in South Africa (DRILL) fellow. DRILL, is a NIH D43 grant (D43TW010131) awarded to UKZN in 2015 to support a research training and induction programme for early career academics. The content is solely the responsibility of the authors and does not necessarily represent the official views of DRILL and the National Institutes of Health."

SHANGASE, M. O.; ISHWARKUMAR, S. \& PILLAY, P. Morfología y morfometría del hueso hioides en una Población Sudafricana Negra. Int. J. Morphol., 39(1):134-137, 2020.

RESUMEN: El hioides es un hueso singular en forma de "U", ubicado en la region del cuello anterior, entre la mandíbula y el cartílago tiroides, que presenta características morfológicas y morfométricas que pueden ayudar a determinar la edad, el sexo y la raza de un individuo. El objetivo de este estudio fue investigar la morfología y los parámetros morfométricos del hueso hioides en una población sudafricana negra de KwaZulu-Natal. Los parámetros morfológicos y morfométricos de los 40 huesos hioides obtenidos del Departamento de Anatomía Clínica de la Universidad de KwaZulu-Natal se clasificaron de acuerdo con Deepak et al. En este análisis, en los hombres el $35 \%$ (7/20) de los huesos hioides tenían forma de 'U' y el $65 \%$ (13/20) tenían forma de 'V' , mientras que en las mujeres, el $70 \%$ (14/20) de los los huesos hioides tenían forma de 'U' y un $30 \%(6 / 20)$ de 'V'. Además, se registró una relación estadísticamente significativa entre la forma del hueso hioides y el sexo. En cuanto a la morfometría, el ancho del hueso hioides fue mayor en los hombres que en las mujeres; la longitud del hueso hioides fue mayor en mujeres que en hombres. Además, el estudio concluye que estos resultados pueden contribuir al conocimiento existente sobre la morfología y morfometría del hueso hioides y pueden ayudar a los procedimientos forenses.

PALABRAS CLAVE: Hueso hioides; Población negra sudafricana; Morfología y morfometría.

\section{REFERENCES}

Balseven-Odabasi, A.; Yalcinozan, E.; Keten, A.; Akçan, R.; Tumer, A. R.; Onan, A.; Canturk, N.; Odabasi, O. \& Dinc, A. H. Age and sex estimation by metric measurements and fusion of hyoid bone in a Turkish population. J. Forensic Leg. Med., 20(5):496-501, 2013.

Deepak, D. H.; Jayaramaiah, K. \& Sathyanarayana, H. S. Determination of sex by shape and size of hyoid bone. J. Indian Acad. Forensic Med., 32(2):145-7, 2013.

Kim, D. I.; Lee, U. Y.; Park, D. K.; Kim, Y. S.; Han, K. H.; Kim, K. H. \& Han, S. H. Morphometrics of the hyoid bone for human sex determination from digital photographs. J. Forensic Sci., 51(5):979-84, 2006.

Kindschuh, S. C.; Dupras, T. L. \& Cowgill, L. W. Determination of sex from the hyoid bone. Am. J. Phys. Anthropol., 143(2):279-84, 2010.

Kindschuh, S. C.; Dupras, T. L. \& Cowgill, L. W. Exploring ancestral variation of the hyoid. J. Forensic Sci., 57(1):41-6, 2012.

Kopuz, C. \& Ortug, G. Variable morphology of the hyoid bone in anatolian population: clinical implications - A cadaveric study. Int. J. Morphol., 34(4):1396-403, 2016.

Leksan, I.; Marcikic', M.; Nikolic', V.; Radic’, R. \& Selthofer, R. Morphological classification and sexual dimorphism of hyoid bone: new approach. Coll. Antropol., 29(1):237-42, 2005.

Logar, C. J.; Peckmann, T. R.; Meek, S. \& Walls, S. G. Determination of sex from the hyoid bone in a contemporary White population. J. Forensic Leg. Med., 39:34-41, 2016.

Moore, K. L.; Dalley II, A. F. \& Agur, A. M. R. Clinically Oriented Anatomy. $7^{\text {th }}$ ed. Philadelphia : Wolters Kluwer Health/Lippincott Williams \& Wilkins, 2014.

Mukhopadhyay, P. Morphometric features and sexual dimorphism of adult hyoid bone: A population specific study with forensic implications. $J$. Forensic Leg. Med., 17(6):321-4, 2010.

Okasi, A.; Sadeghian, M. H.; Behnoush, B. \& Rad, A. S. Sex identification by morphometric study of hyoid bone. Int. J. Med. Toxicol. Forensic Med., 8(4):145-50, 2018.

Reesink, E. M.; Van Immerseel, A. A. H.; Brand, R. \& Bruintjes, T. D. Sexual dimorphism of the hyoid bone? Int. J. Osteoarchaeol., 9(5):357-60, 1999.

Soltani, S.; Aghakhani, K. \& Fallah, F. Sex prediction potential of hyoid metric measurements in Iranian adults. Leg. Med., 25:6-10, 2017.

Torimitsu, S.; Makino, Y.; Saitoh, H.; Ishii, N.; Yajima, D.; Inokuchi, G.; Motomura, A.; Chiba, F.; Yamaguchi, R.; Hoshioka, Y.; et al. Determination of sex on the basis of hyoid bone measurements in a Japanese population using multidetector computed tomography. Int. J. Legal Med., 132(3):907-14, 2018.

Ubelaker, D. H. \& DeGaglia, C. M. Population variation in skeletal sexual dimorphism. Forensic Sci. Int., 278:407.e1-407.e7, 2017.

Corresponding author:

Dr P. Pillay

Department of Clinical Anatomy

School of Laboratory Medicine and Medical Sciences

College of Health Sciences

University of KwaZulu-Natal

Private Bag X54001

Durban 4000

SOUTH AFRICA

Email: soobramoneypa@ukzn.ac.za 